\title{
Conjugate Addition of Indoles to $\alpha, \beta$-Unsaturated Ketones Using Bismuth (III) Bromide
}

\section{Tyler J. Rauwolf, Zhijia Geng, Zachary P. Kinney, Jared L. Renfroe, Jack H. Roireau, Lauren T. Yep, Ram S. Mohan}

Laboratory for Environmentally Friendly Organic Synthesis, Department of Chemistry, Illinois Wesleyan University, Bloomington, IL, USA

Email: rmohan@iwu.edu

How to cite this paper: Rauwolf, T.J., Geng, Z.J., Kinney, Z.P., Renfroe, J.L., Roireau, J.H., Yep, L.T. and Mohan, R.S. (2019) Conjugate Addition of Indoles to $\alpha, \beta$-Unsaturated Ketones Using Bismuth (III) Bromide. Green and Sustainable Chemistry, 9, 79-84.

https://doi.org/10.4236/gsc.2019.93005

Received: June 10, 2019

Accepted: July 15, 2019

Published: July 18, 2019

Copyright ( $\odot 2019$ by author(s) and Scientific Research Publishing Inc. This work is licensed under the Creative Commons Attribution International License (CC BY 4.0).

http://creativecommons.org/licenses/by/4.0/

\begin{abstract}
An efficient method for the conjugate addition of indoles to a variety of chalcones using $\mathrm{BiBr}_{3}$ in ethanol (190 proof) is reported. Products are isolated by a simple procedure that avoids an aqueous work up and extensive chromatography, thus minimizing waste. Bismuth (III) compounds are especially attractive from a green chemistry perspective because they are remarkably nontoxic, non-corrosive and relatively inexpensive.
\end{abstract}

\section{Keywords}

Bismuth, Bismuth Bromide, Conjugate Addition, Green Chemistry, Indoles

Indoles and their derivatives are of considerable interest in medicinal chemistry due to the wide range of biological activity they exhibit. Indoles undergo electrophilic substitution at the 3-position and hence a variety of methods have been developed for the synthesis of 3-substituted indoles [1]-[8]. The conjugate addition of indoles to chalcones (substituted phenyl styryl ketones) leads to 3-indolyl ketones, compounds that exhibit biological activity [9]. Hence a variety of catalysts have been used to catalyze such additions. Some examples include $\mathrm{FeCl}_{3}$ [10] [11], cesium salt of tungstophosphoric acid [12], cellulose sulfuric acid [13], $\mathrm{KHSO}_{4}$ [14], potassium superoxide- $\mathrm{Et}{ }_{4} \mathrm{NBr}$ [15], poly\{N, N'-dibromo-N-ethylbenzene-1,3-disulfonamide\} [16], silica sulfuric acid [17], $\mathrm{CuCl}_{2}$ [18], cyanuric chloride [19], $\mathrm{Bu}_{4} \mathrm{NHSO}_{4}$ [20], $\mathrm{GaCl}_{3}$ [21], $\mathrm{Br}_{2}$ [22] and $\mathrm{I}_{2}$ [23] [24] [25]. Enantioselective conjugate addition of indoles to chalcones have also been developed using $\mathrm{Zr}\left(\mathrm{O}^{\mathrm{t}} \mathrm{Bu}\right)_{4}$-BINOL and $\mathrm{N}, \mathrm{N}^{\prime}$-dioxide-Sc(OTf $)_{3}$ complexes [26] [27]. The 
conjugate addition of indoles to simple enones (but not chalcones) has been reported using $\mathrm{Bi}\left(\mathrm{NO}_{3}\right)_{3} \cdot 5 \mathrm{H}_{2} \mathrm{O}$ as a catalyst [28] [29]. The conjugate addition of indole to chalcone has also been reported with $\mathrm{Bi}(\mathrm{OTf})_{3}$ as a catalyst in $\mathrm{CH}_{3} \mathrm{CN}$ as the solvent [30] [31]. These bismuth salts-catalyzed methods involve product isolation via an aqueous work-up followed by chromatographic purification that generates significant solvent waste. In an effort to develop a method in a green solvent that would eliminate waste from aqueous work-up and extensive column chromatography, we investigated the utility of $\mathrm{BiBr}_{3}$ as a catalyst in ethanol (190 proof) for the addition of indoles to chalcones. Bismuth compounds are remarkably nontoxic, relatively stable to moisture and air, and easy to handle. As a result there has been considerable interest in the use of bismuth compounds in organic synthesis in the last two decades [32] [33] [34] [35] [36]. Herein we report the conjugate addition of indoles to a variety of chalcones using bismuth bromide, $\mathrm{BiBr}_{3}$, in a relatively green and inexpensive solvent, ethanol (190 proof). The product was isolated by evaporation of the solvent, filtration of the residue (using minimal $\mathrm{CH}_{2} \mathrm{Cl}_{2}$ ) through a short plug of silica to remove the catalyst, and concentration of the filtrate followed by trituration of the residue with $\mathrm{CH}_{3} \mathrm{CH}_{2} \mathrm{OH}$ (190 proof). This method avoids the use of elaborate chromatography for product purification and also eliminates an aqueous waste stream. During optimization of the reaction conditions we found that both 2-propanol ( ${ }^{\mathrm{PrOH}}$ ) and absolute ethanol are also suitable solvents, but we chose $\mathrm{CH}_{3} \mathrm{CH}_{2} \mathrm{OH}$ (190 proof) as it was easier to remove than ${ }^{i} \mathrm{PrOH}$, and is considerably cheaper and easier to obtain than absolute ethanol. The results are summarized in Table 1. Electron withdrawing groups on the phenyl ring proximal to the carbonyl required a higher catalyst loading for optimal reaction time and yield (entries 8, 9, 11 and 12). Similarly, a strongly electron donating group on the phenyl group distal to the carbonyl (entry 4) required a higher catalyst loading. When the nucleophilicity of the indole was lowered by an electron withdrawing group (entry 3 ) a higher catalyst loading was required. A solution of $\mathrm{BiBr}_{3}$ in $\mathrm{CH}_{3} \mathrm{CH}_{2} \mathrm{OH}$ (190 proof) has a $\mathrm{pH}$ of $\sim 3.0$, suggesting that some $\mathrm{HBr}$ is generated by hydrolysis. Hence, Bronsted acid catalysis by $\mathrm{HBr}$ cannot be ruled out. When the conjugate addition of indole to 4'-methylchalcone (Table 1, entry 6) was attempted in the presence of Proton-Sponge ${ }^{\infty}$ [37], 1,8-bis(dimethylamino) naphthalene, (0.60 equivalents) no product formed, and the starting materials were recovered. Similarly, no product was formed when the same reaction was carried out in the presence of solid $\mathrm{K}_{2} \mathrm{CO}_{3}$. Both these results suggest that the primary role of $\mathrm{BiBr}_{3}$ is to act as a convenient source of $\mathrm{HBr}$ [22]. Aqueous $\mathrm{HBr}$ is very corrosive and difficult to handle unlike $\mathrm{BiBr}_{3}$, which is an air stable and easy to handle solid.

A representative procedure is given here: A mixture of 4-methylchalcone $(0.5000 \mathrm{~g}, 2.2493 \mathrm{mmol})$ and indole $(0.3162 \mathrm{~g}, 2.6992 \mathrm{mmol}, 1.2$ equivalents $)$ in $\mathrm{CH}_{3} \mathrm{CH}_{2} \mathrm{OH}$ (190 proof, $10.0 \mathrm{~mL}$ ) was stirred at room temperature as $\mathrm{BiBr}_{3}$ (0.2018 g, $0.4497 \mathrm{mmol}, 20.0 \mathrm{~mol} \%$ ) was added. The mixture was then heated at $70^{\circ} \mathrm{C}$ (temperature controlled hot plate), and the reaction progress was monitored 
Table 1. Addition of indoles to chalcones using $\mathrm{BiBr}_{3}$.

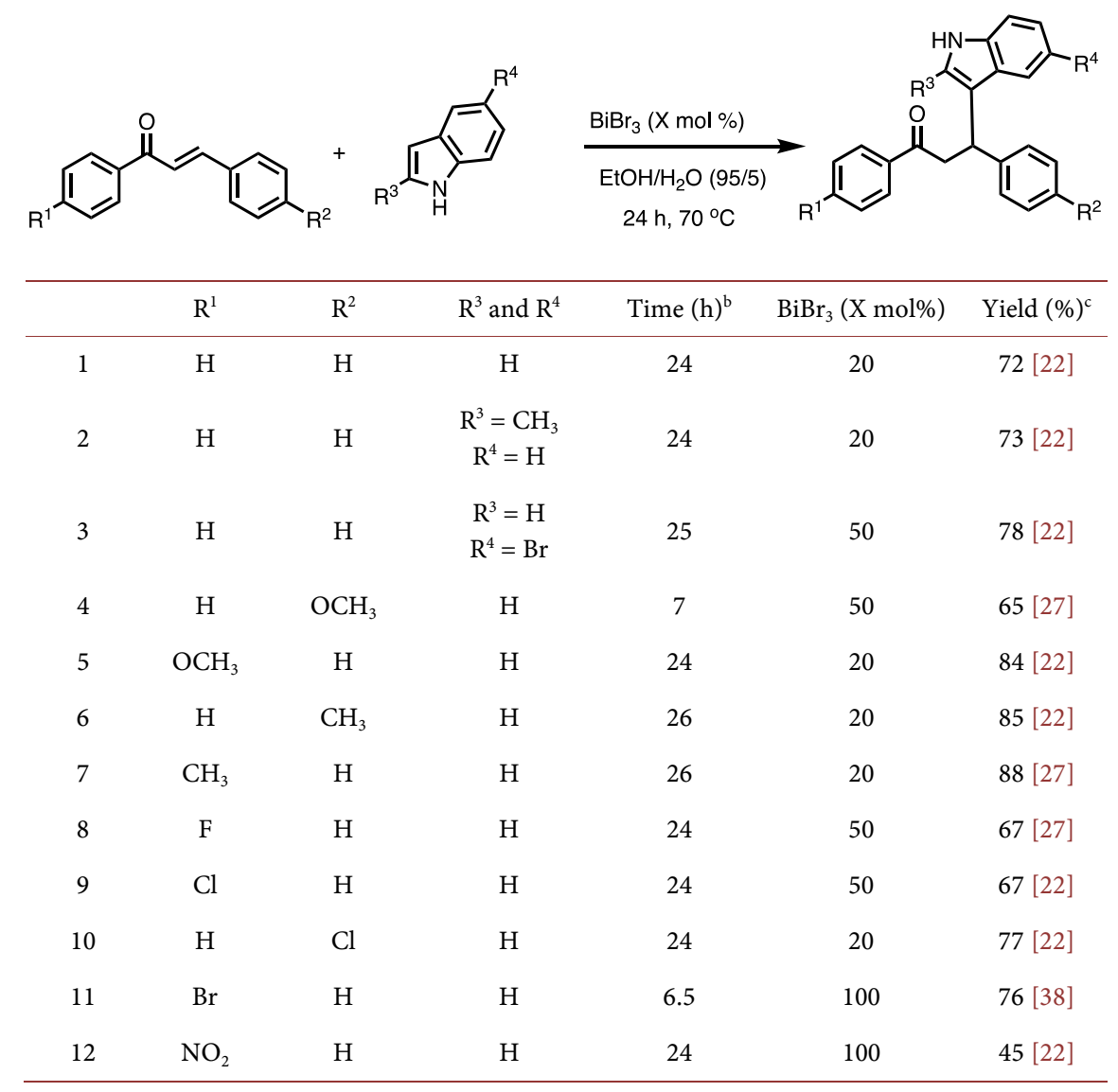

${ }^{\mathrm{a}}$ Chalcones were purchased commercially or synthesized in lab using standard procedures [39]. ${ }^{\mathrm{b}}$ Reaction progress was monitored using TLC and spots were visualized under UV light, and by spraying with phosphomolybdic acid followed by heating. 'Refers to yield of isolated product that was deemed to be $\geq 98 \%$ by ${ }^{1} \mathrm{H}$ and ${ }^{13} \mathrm{C}$ NMR spectroscopy. All products have been previously reported in the literature. Superscript against yield refers to literature reference for spectral data.

by TLC (20/80, EtOAc/heptane). After $26 \mathrm{~h}$, the reaction was cooled to room temperature, and concentrated on a rotary evaporator to yield a pale red solid. The solid was filtered through a plug of silica gel $\left(7.00 \mathrm{~g}, 20 \mathrm{~mL}\right.$ of $\left.\mathrm{CH}_{2} \mathrm{Cl}_{2}\right)$. The filtrate was concentrated on a rotary evaporator to yield a pale-yellow oily residue that was triturated with $\mathrm{CH}_{3} \mathrm{CH}_{2} \mathrm{OH}$ (190 proof, $6 \mathrm{~mL}$ ) to yield $0.6500 \mathrm{~g}$ (85\%) of a pale-pink solid. The product was characterized by comparison of ${ }^{1} \mathrm{H}$ and ${ }^{13} \mathrm{C}$ NMR spectral data to literature data and deemed to be $>98 \%$ pure.

In summary, a new procedure for the conjugate addition of indoles to a variety of chalcones using $\mathrm{BiBr}_{3}$ has been developed. The low toxicity of bismuth salts, and a product isolation method that avoids waste generated from an aqueous work up and elaborate column chromatography, make this procedure particularly attractive from a green chemistry perspective.

\section{Acknowledgements}

This material is based upon work supported by the National Science Foundation under CHE-1229133, which funded the purchase of a $400 \mathrm{MHz}$ NMR spec- 
trometer. RM would like to acknowledge an Artistic and Scholarly grant from Illinois Wesleyan University.

\section{Conflicts of Interest}

The authors declare no conflicts of interest regarding the publication of this paper.

\section{References}

[1] Sundberg, R.J. (1970) The Chemistry of Indoles. Academic Press, New York.

[2] Sundberg, R.J. (1996) Indoles. Academic Press, London.

[3] Gribble, G.W. (2000) Recent Developments in Indole Ring Synthesis-Methodology and Applications. Journal of the Chemical Society, Perkin Transactions, 1, 1045-1075. https://doi.org/10.1039/a909834h

[4] Cacchi, S. and Fabrizi, G. (2005) Synthesis and Functionalization of Indoles through Palladium-Catalyzed Reactions. Chemical Reviews, 105, 2873-2920. https://doi.org/10.1021/cr040639b

[5] Cacchi, S. and Fabrizi, G. (2011) Update 1 of: Synthesis and Functionalization of Indoles through Palladium-Catalyzed Reactions. Chemical Reviews, 111, PR215PR283. https://doi.org/10.1021/cr100403z

[6] Humphrey, G.R. and Kuethe, J.T. (2006) Practical Methodologies for the Synthesis of Indoles. Chemical Reviews, 106, 2875-2911. https://doi.org/10.1021/cr0505270

[7] Taber, D.F. and Tirunahari, P.K. (2011) Indole Synthesis: A Review and Proposed Classification. Tetrahedron, 67, 7195-7210. https://doi.org/10.1016/j.tet.2011.06.040

[8] Bandini, M. and Eichholzer, A. (2009) Catalytic Functionalization of Indoles in a New Dimension. Angewandte Chemie International Edition, 48, 9608-9644. https://doi.org/10.1002/anie.200901843

[9] Siddappa, M.K., Satyanarayan, N.D., Yarbagi, K.M. and Jagadeesha, A.H. (2016) Anti-Proliferative and ADMET Screening of Novel 3-(1H-Indol-3-yl)-1, 3-diphenylpropan-1-one Derivatives. Cogent Chemistry, 2, Article ID: 1172542. https://doi.org/10.1080/23312009.2016.1172542

[10] Anpat, S., Dabholkar, V.V., Gulve, S. and Krishnan, K. (2018) Iron(III) Chloride Hexahydrate Catalysed Efficient Synthesis of 3-Substituted Indoles via Michael Addition Reaction. Journal of Chemistry and Chemical Sciences, 8, 671-676. https://doi.org/10.29055/jccs/624

[11] Liang, L., Liu, Q., Zhang, J., Wang, F. and Yuan, Y. (2013) Efficient Iron-Catalyzed Michael Addition of Indole to Nitroolefins under Solvent-Free Conditions. Research on Chemical Intermediates, 39, 1957-1962. https://doi.org/10.1007/s11164-012-0728-1

[12] Khabazzadeh, H., Kermany, E.T. and Eghbali, M. (2016) $\mathrm{Cs}_{2.5} \mathrm{H}_{0.5} \mathrm{PW}_{12} \mathrm{O}_{40}$-Catalyzed Conjugate Addition of Indole to Unsaturated Ketones. Arabian Journal of Chemis try, 9, S639-S662. https://doi.org/10.1016/j.arabjc.2011.07.012

[13] Murthy, Y.L.N., Choppara, P., Prasad, Y.V. and Ranjan, T.J.U. (2014) Synthesis, Characterisation of $\beta$-Indolyketones and the Effect of Lipophilicity on the Antimicrobial Activity. Current Pharmaceutical Analysis, 10, 284-292. https://doi.org/10.2174/1573412910666140630165745

[14] Devi, A.S., Helissey, P., Nongkhlaw, R.L. and Vishwakarma, J.N. (2013) $\mathrm{KHSO}_{4-}$ Assisted Michael Addition-Elimination Reactions of Indole with 3-Dimethylamino- 
1-phenylprop-2-en-1-ones in Water: An Environmentally Friendly Synthesis of Novel 3-Indolychalcones. Synthetic Communications, 43, 1653-1660. https://doi.org/10.1080/00397911.2012.658946

[15] Singh, S.K. and Singh, K.N. (2012) An Efficient and Mild Superoxide Induced Michael Addition of Indoles to $\alpha, \beta$-Unsaturated Ketones. Journal of Indian Chemical Society, 89, 401. https://doi.org/10.1002/chin.201246118

[16] Ghorbani-Vaghei, R., Hajinazari, S. and Engashte, M. (2012) Poly (N, N'-dibromoN-ethyl-benzene-1,3-disulfonamide), N,N,N',N'-Tetrabromobenzene 1,3-disulfonamide as New Reagents for Conjugate Addition of Indole, Pyrrole with $\alpha, \beta$-Unsaturated Ketones. Journal of Iran Chemical Society, 9, 655-660. https://doi.org/10.1007/s13738-012-0087-2

[17] Zolfigol, M.A., Veisi, H., Mohanazadeh, F. and Sedrpoushan, A. (2011) Synthesis and Application of Modified Silica Sulfuric Acid as a Solid Acid Heterogeneous Catalyst in Michael Addition Reactions. Journal of Heterocyclic Chemistry, 48, 977-986. https://doi.org/10.1002/jhet.659

[18] Kanwar, D., Rani, R., Agarwal, J. and Peddinti, R.K. (2010) Copper (II) Chloride Catalyzed Friedel-Crafts-Type Conjugate Addition of Indoles to $\alpha, \beta$-Unsaturated Enones: Synthesis of 3-Substitued Indoles. Indian Journal of Chemistry, 49B, 1290 1299. https://doi.org/10.1002/chin.201103117

[19] Ghorbani-Vaghei, R. and Veisi, H. (2009) The Michael Addition of Indoles and Pyrrole to $\alpha, \beta$-Unsaturated Ketones and Double-Conjugate 1,4-Addition of Indoles to Symmetric Enones Promoted by Pulverization-Activation Method and ThiaMichael Addition Catalyzed by Wet Cyanuric Chloride. Molecular Diversity, 14, 385-392. https://doi.org/10.1007/s11030-009-9184-2

[20] Damodiran, M., Kumar, R.S., Sivakumar, P.M., Doble, M. and Perumal, P.T. (2009) A Simple Protocol for the Michael Addition of Indoles with Electron Deficient Olefins Catalyzed by TBAHS in Aqueous Media and Their Broad Spectrum Antibacterial Activity. Journal of Chemical Sciences, 121, 65-73. https://doi.org/10.1007/s12039-009-0007-x

[21] Xu, R., Ding, J.C., Chen, X.A., Liu, M.C. and Wu, H.Y. (2009) Gallium Trichloride-Catalyzed Conjugate Addition of Indole and Pyrrole to $\alpha, \beta$-Unsaturated Ketones in Aqueous Media. Chinese Chemical Letters, 20, 676-679. https://doi.org/10.1016/j.cclet.2009.01.028

[22] Liang, D., Li. X., Zhang, W., Li, Y., Zhang, M. and Cheng, P. (2016) $\mathrm{Br}_{2}$ as a Novel Lewis Acid Catalyst for Friedel-Crafts Alkylation of Indoles with $\alpha, \beta$-Unsaturated Ketones. Tetrahedron Letters, 57, 1027-1030. https://doi.org/10.1016/j.tetlet.2016.01.078

[23] Heiden, D.V.D, Bozkus, S., Klussmann, M. and Breugst, M. (2017) Reaction Mechanism of Iodine-Catalyzed Michael Additions. The Journal of Organic Chemistry, 82, 4037-4043. https://doi.org/10.1021/acs.joc.7b00445

[24] Ko, S., Lin, C., Tu, Z., Wang, Y.-F., Wang, C.-C. and Yao, C.-F. (2006) CAN and Iodine-Catalyzed Reaction of Indole or 1-Methylindole with $\alpha, \beta$-Unsaturated Ketone or Aldehyde. Tetrahedron Letters, 47, 487-492. https://doi.org/10.1016/j.tetlet.2005.11.058

[25] Ji, S.-J., Loh, T.-P. and Wang, S.-Y. (2003) The Michael Addition of Indole to $\alpha$, $\beta$-Unsaturated Ketones Catalyzed by Iodine at Room Temperature. Synlett, 15, 2377-2379. https://doi.org/10.1055/s-2003-42105

[26] Blay, G., Fernández, I., Pedro, J.R. and Vila, C. (2007) Highly Enantioselective Friedel-Crafts Alkylations of Indoles with Simple Enones Catalyzed by Zirconium 
(IV)-BINOL Complexes. Organic Letters, 9, 2601-2604. https://doi.org/10.1021/ol0710820

[27] Wang, W., Liu, X., Cao, W., Wang, J., Lin, L. and Feng, X. (2010) Highly Enantioselective Synthesis of $\beta$-Heteroaryl-Substituted Dihydrochalcones through Friedel-Crafts Alkylation of Indoles and Pyrrole. Chemistry-A European Journal, 16, 1664-1669. https://doi.org/10.1002/chem.200902355

[28] Srivastava, N. and Banik, B.K. (2003) Bismuth Nitrate-Catalyzed Versatile Michael Reactions. The Journal of Organic Chemistry, 68, 2109-2114. https://doi.org/10.1021/jo026550s

[29] Banik, B.K., Garcia, I. and Morales, F.R. (2007) Bismuth Nitrate-Catalyzed Versatile Michael Reactions. Heterocycles, 71, 919. https://doi.org/10.3987/COM-06-10957

[30] Alam, M., Varala, R. and Adapa, S.R. (2003) Conjugate Addition of Indoles and Thiols with Electron-Deficient Olefins Catalyzed by $\mathrm{Bi}(\mathrm{OTf})_{3}$. Tetrahedron Letters, 44, 5115-5119. https://doi.org/10.1016/S0040-4039(03)01089-X

[31] Reddy, A., Ravinder, K., Goud, T., Krishnaiah, P., Raju, T. and Venkateswarlu, Y. (2003) Bismuth Triflate Catalyzed Conjugate Addition of Indoles to $\alpha$, $\beta$-Enones. Tetrahedron Letters, 44, 6257-6260. https://doi.org/10.1016/S0040-4039(03)01555-7

[32] Mohan, R. (2010) Green Bismuth. Nature Chemistry, 2, 336. https://doi.org/10.1038/nchem.609

[33] Bothwell, J.M., Krabbe, S.W. and Mohan, R.S. (2011) Applications of Bismuth(III) Compounds in Organic Synthesis. Chemical Society Reviews, 40, 4649-4707. https://doi.org/10.1039/c0cs00206b

[34] Salvador, J.A.R., Silvestre, S.M., Pinto, R.M.A., Santos, R.C. and LeRoux, C. (2012) New Applications for Bismuth (III) Salts in Organic Synthesis: From Bulk Chemicals to Steroid and Terpene Chemistry. Topics in Current Chemistry, 311, 143-178. https://doi.org/10.1007/128_2011_170

[35] Ueno, M., Ohmura, S.D., Wada, M. and Miyoshi, N. (2019) Aerobic Oxidation of Alcohols using Bismuth Bromide as a Catalyst. Tetrahedron Letters, 60, 570-573. https://doi.org/10.1016/j.tetlet.2019.01.034

[36] Zhu, S., Tran, A.T., Hirokami, Y., Gontard, G., Khaled, O., Zhang, Y., Kato, A., Blériot, Y. and Sollogoub, M. (2019) $\mathrm{Bi}\left(\mathrm{OTf}_{3}\right.$-Mediated Intramolecular Epoxide Opening for Bicyclic Azepane Synthesis. Journal of Carbohydrate Chemistry, 38, 139-149. https://doi.org/10.1080/07328303.2019.1581887

[37] Brzeziński, B., Grech, E., Malarski, Z. and Sobczyk, L. (1991) Protonation of 1,8-bis(dimethylamino)naphthalene by Various Acids in Acetonitrile. Journal of the Chemical Society, Perkin Transactions, 2, 857-859. https://doi.org/10.1039/P29910000857

[38] Subramanian, T., Kumarraja, M. and Pitchumani, K. (2012) Al-MCM-41 as a Mild and Eco Friendly Catalyst for Michael Addition of Indole to, $\alpha, \beta$-Unsaturated Ketones. Journal of Molecular Catalysis A: Chemical, 363-364, 115-121. https://doi.org/10.1016/j.molcata.2012.05.024

[39] Furniss, B.S., Hannaford, A.J., Smith, P.W.G. and Tatchell, A.R. (1989) Vogel's Text Book of Practical Organic Chemistry. 5th Edition, Longman, New York. 